\title{
Fertility in the Nordic Countries
}

\section{The Family Size in Denmark}

\author{
BY OLE BERTELSEN
}

The Danish National Institute of Social Research

\section{Development up to 1970}

The fall in fertility which was experienced in Denmark during the last century where the family size has been reduced from having consisted, on an average, of $5-6$ children to now $2-3$ children, must first of all be considered in the light of the gradual transition from an agrarian to an industrialized society.

For the family this change in living conditions has had the effect that the economic role which the children played for the family has gradually disappeared. One can in particular point to the fact that the family no longer functions as a production unit, and that public authorities are now to a large extent responsible for support during illness and in old age. The development has thus involved that economically the importance of the children has passed from the individual family to society as a whole. Consequently it is today of importance for society whether the yearly birth rates are of such magnitude that henceforth there will be a reasonable proportion between the productive age groups and the age groups who are to be supported. This ratio can, however, to a certain extent be modified through automation and an increase in production per industrial worker, and the possibility of importing foreign labour. Yet there is hardly any doubt that a heavy fall in the birth rate is unfortunate for the economy of the country if the objective is economic growth.

Beyond the fact that fertility in Denmark has been influenced by the transition from an agrarian to an industrialized society, tendencies for the birth rate to have been sensitive to temporary economic conditions can furthermore be observed. If one considers the age-conditioned fertility quotients (Figure 1) for the last 60 years, this tendency is clearly visible. Thus the depression in the 1.930's was followed by a decline in the birth rate, whilst the period around the end of the Second World War when employment had a boom was followed by a heavy rise in the birth rate. This temporal coincidence between the occupational situation and the birth rate seems, however, not to have applied to the period at the end of the 1960's. Here it was a question of full employment and a fall in the birth rate. This reduction in the birth rate, on the other hand, coincides with the release of the contraceptive pill as a means of contraception. 
If one looks a little closer at the age-conditioned fertility quotients (Figure 1), it appears that in the case of women over 30 years it is a question of a continuation of the reduction in fertility which had been dwindling since the turn of the century - thus for these women the introduction of the pill did not alter this development. Among the younger women a fall in fertility was experienced at the end of the 1960's. This was presumably due chiefly to a postponement of births to a date more convenient for the women. One cannot, however, quite exclude the possibility that there may be a limitation of the birth rate also among women under 30 .

Moreover Table 1, which covers the last 15 years, shows that the average age of women at the time of giving birth tends to be falling. Here it appears that the proportion of women over 30 years giving birth has been halved during these 15 years, and that the development has been stable. Table 2 shows that the development with regard to the reduction of the family size has also been

Fig u re 1. Number of births per 1,000 women in the individual age groups for the period 1910-1970.

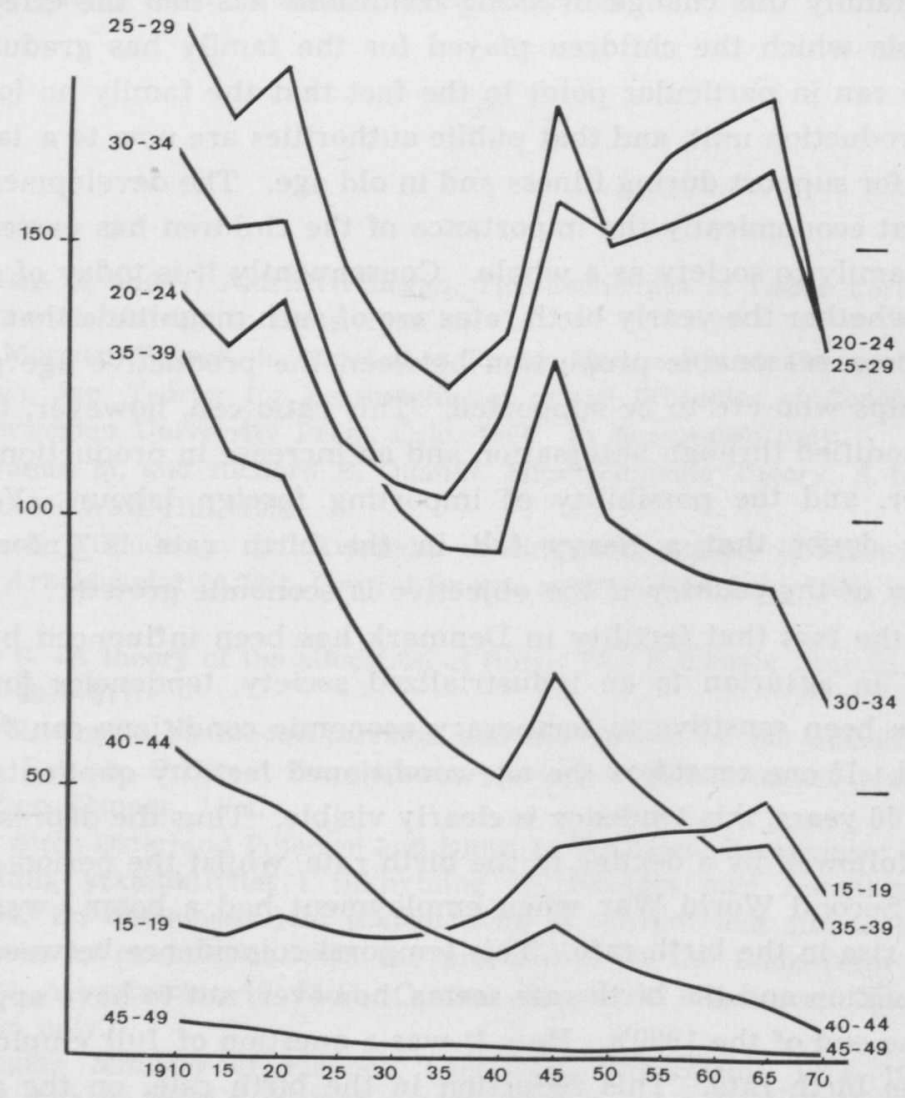

Source: The Danish Bureau of Statistics. 
stable. As will be seen from this table the proportion of the fourth birth numbers has been more than halved during the last 15 years.

Thus it has been characteristic of the more recent years that the introduction of the contraceptive pill in 1966 did not alter the development in fertility which had been going on during the last century, viz. that the family size is becoming constantly smaller, that the average age of women giving birth is falling stimultaneously with a concentration of births on the age interval 20 29 years. The question which therefore suggests itself is whether this development will continue, or whether there may be conditions which will arrest this development and if so what conditions. This, among other things, is what it has been possible to elucidate through the Danish investigation of fertility.

T a ble 1. The annual number of children born living, by the mother's age, for the period 1955-1970.

Year

\begin{tabular}{|c|c|c|c|c|c|c|c|c|}
\hline & \multicolumn{6}{|c|}{ Mother's age } & \multirow[t]{2}{*}{ Total } & \multirow{2}{*}{$\begin{array}{l}\text { Number } \\
\text { of births }\end{array}$} \\
\hline & $\begin{array}{c}15-19 \\
\text { yrs }\end{array}$ & $\begin{array}{c}20-24 \\
\text { yrs }\end{array}$ & $\begin{array}{c}25-29 \\
\text { yrs }\end{array}$ & $\begin{array}{c}30-34 \\
\text { yrs }\end{array}$ & $\begin{array}{c}35-39 \\
\text { yrs }\end{array}$ & $\begin{array}{l}40 \mathrm{yrs} \\
\text { and more }\end{array}$ & & \\
\hline 1955 & $6 \%$ & $31 \%$ & $30 \%$ & $20 \%$ & $9 \%$ & $4 \%$ & $100 \%$ & 76,845 \\
\hline 1956 & $6 \%$ & $31 \%$ & $30 \%$ & $19 \%$ & $10 \%$ & $4 \%$ & $100 \%$ & 76,725 \\
\hline 1957 & $7 \%$ & $32 \%$ & $30 \%$ & $19 \%$ & $9 \%$ & $3 \%$ & $100 \%$ & 75,264 \\
\hline 1958 & $9 \%$ & $33 \%$ & $29 \%$ & $18 \%$ & $9 \%$ & $2 \%$ & $100 \%$ & 74,681 \\
\hline 1959 & $10 \%$ & $33 \%$ & $29 \%$ & $17 \%$ & $8 \%$ & $3 \%$ & $100 \%$ & 73,928 \\
\hline 1960 & $10 \%$ & $34 \%$ & $29 \%$ & $17 \%$ & $8 \%$ & $2 \%$ & $100 \%$ & 76,077 \\
\hline 1961 & $11 \%$ & $34 \%$ & $29 \%$ & $16 \%$ & $8 \%$ & $2 \%$ & $100 \%$ & 76,439 \\
\hline 1962 & $11 \%$ & $35 \%$ & $29 \%$ & $16 \%$ & $7 \%$ & $2 \%$ & $100 \%$ & 77,808 \\
\hline 1963 & $12 \%$ & $35 \%$ & $29 \%$ & $15 \%$ & $7 \%$ & $2 \%$ & $100 \%$ & 82,413 \\
\hline 1964 & $12 \%$ & $36 \%$ & $29 \%$ & $15 \%$ & $7 \%$ & $1 \%$ & $100 \%$ & 83,356 \\
\hline 1965 & $12 \%$ & $38 \%$ & $28 \%$ & $14 \%$ & $6 \%$ & $2 \%$ & $100 \%$ & 85,796 \\
\hline 1966 & $11 \%$ & $39 \%$ & $28 \%$ & $14 \%$ & $6 \%$ & $2 \%$ & $100 \%$ & 88,332 \\
\hline 1967 & $11 \%$ & $40 \%$ & $28 \%$ & $13 \%$ & $6 \%$ & $2 \%$ & $100 \%$ & 81,410 \\
\hline 1968 & $11 \%$ & $40 \%$ & $29 \%$ & $14 \%$ & $5 \%$ & $1 \%$ & $100 \%$ & 74,543 \\
\hline 1969 & $10 \%$ & $39 \%$ & $31 \%$ & $14 \%$ & $5 \%$ & $1 \%$ & $100 \%$ & 71,298 \\
\hline 1970 & $8 \%$ & $38 \%$ & $34 \%$ & $14 \%$ & $5 \%$ & $1 \%$ & $100 \%$ & 70,802 \\
\hline
\end{tabular}

Source: Movements of the Population 1955-1970. Statistical information. The Danish Bureau of Statistics.

\section{The Danish Fertility Investigation in 1970}

The investigation was carried out by The Danish National Institute of Social Research, The Danish Bureau of Statistics and the Public Health Board working together. The aims of the investigation were: (1) to collect information which can contribute to improved population prognoses (2) to collect information about the use and dissemination of contraceptives, in particular contra- 
Table 2. Children born living in marriage, by the child's birth number (number of mother's pregnancies, including abortions) for the period 1955-1970.

\begin{tabular}{|c|c|c|c|c|c|c|c|c|}
\hline & & & & num & & & Total & Number \\
\hline & 1 & 2 & 3 & 4 & 5 & $6 *$ & & of births \\
\hline Year & $\%$ & $\%$ & $\%$ & $\%$ & $\%$ & $\%$ & $\%$ & \\
\hline 1955 & 30 & 31 & 19 & 10 & 5 & 5 & 100 & 71,748 \\
\hline 1956 & 30 & 31 & 19 & 10 & 5 & 5 & 100 & 71,489 \\
\hline 1957 & 31 & 31 & 19 & 10 & 5 & 4 & 100 & 70,035 \\
\hline 1958 & 30 & 32 & 19 & 10 & 5 & 4 & 100 & 69,288 \\
\hline 1959 & 31 & 31 & 19 & 9 & 5 & 5 & 100 & 68,500 \\
\hline 1960 & 31 & 31 & 19 & 9 & 5 & 5 & 100 & 70,124 \\
\hline 1961 & 32 & 31 & 19 & 9 & 5 & 4 & 100 & 70,286 \\
\hline 1962 & 32 & 31 & 19 & 9 & 5 & 4 & 100 & 71,318 \\
\hline 1963 & 33 & 32 & 19 & 9 & 4 & 3 & 100 & 75,096 \\
\hline 1964 & 33 & 32 & 19 & 9 & 4 & 3 & 100 & 75,572 \\
\hline 1965 & 33 & 33 & 19 & 9 & 4 & 2 & 100 & 77,684 \\
\hline 1966 & 34 & 33 & 18 & 8 & 4 & 3 & 100 & 79,349 \\
\hline 1967 & 35 & 34 & 18 & 8 & 3 & 2 & 100 & 72,388 \\
\hline $1968 *$ & 42 & 35 & 15 & 5 & 2 & 1 & 100 & 62,402 \\
\hline $1969 *$ & 38 & 37 & 16 & 5 & 2 & 1 & 99 & 63,244 \\
\hline 1970 * & 38 & 39 & 16 & 5 & 2 & 1 & 101 & 62,991 \\
\hline
\end{tabular}

* after 1968 the birth number is equal to the number of living births.

Source: Movements of the Population 1955-1970. Statistical information. The Danish Bureau of Statistics.

ceptive pills and (3) to get a better insight into what processes lead to different family patterns.

At the planning of this investigation the instructions of the United Nations Working Group on Social Demography have to a large extent been followed in order thereby to facilitate comparative fertility studies.

Interviews were carried out with 2397 married women, a representative selection of married women ranging in age from 15 to 49 years, 314 unmarried women representing the age group 18-24 years, and 330 husbands of the 20 29-year-old married women. An error in the selection of persons to be interviewed in the metropolitan boroughs Copenhagen, Frederiksberg and Gentofte has involved that the interviews in these boroughs did not take place until 1972 . This supplementing material has not been included in this article.

\section{The Expected Family Size}

It has previously been shown in the USA ${ }^{1}$ that the number of children the women themselves state they expect to have generally speaking correspond to

1 Whelpton, Campbell and Patterson: Fertility and Family Planning in the United States. New Jersey 1966. 
the total number of children they will later have. In a follow-up of The Danish National Institute of Social Research's study of Married Women in Family and Employment from $1965^{2}$ it was found that also Danish women broadly speaking were able to predict how many children they would have.

It has therefore been assumed that also in the fertility study the women's expectations of family size is a very good prediction of the actual future family size. This especially holds good when here, as in the American investigation, fairly large groups of women are considered, and accordingly the uncertainty which for the individual woman would be connected with the prediction of the number of children she will have can to a certain extent be disregarded. It can, moreover, be reasonably assumed that the development of recent years with regard to improved contraceptive techniques, the introduction of the contraceptive pill and the coil and the liberalization of abortion law provisions on the one hand and medical progress as to remedying childlessness on the other hand will have the effect that Danish women will to a higher degree than previously be able to realize their expectations of the future family size.

The expected number of children is based on the woman's own information of how many children she had when the interview took place and how many more she expected to have. The statement in Table 3 has been prepared on the basis of the women's responses to these two questions. Women over 34 have not been included in the analysis; this is primarlily due to our wish of elucidating the future development of the family size.

$\mathrm{Table} 3$. Statement of the expected number of children among married women aged $15-34$.

$\begin{array}{lr}\text { Expected number of children } & \text { Per cent } \\ 0 \text { children } & 1 \\ 1 \text { child } & 4 \\ 1-2,2 \text { children } & 42 \\ 2-3,3 \text { children } & 33 \\ 3-4,4 \text { children } & 11 \\ 4-5,5 \text { children } & 2 \\ 5 \text { children } & 1 \\ \text { Other figures, do not know } & \\ \quad \text { and not stated } & 8 \\ \text { T o t a } 1 & 102\end{array}$

Number of interviewed women 1759

NB. 3 per cent of women comprised by the investigation have in their response to the number of children they expect to have stated intervals.

2 Bertelsen: Opfølgning af Gifte Kvinder undersøgelsen (Follow-up study of Married Women). Material at The Danish National Institute of Social Research, 1969. 


\section{Main Results of the Fertility Investigation}

About three-fourths of all married women between 15 and 34 years have or expect to have two or three children; the proportion who expect two children is a little larger than the proportion who expect to have three, and this ratio is independent of the woman's age and social background. There are still a negligible number of women who do not expect any children or only one child, and there are not many either who expect four or - rarely - more children.

The ratio between the slightly larger proportion expecting two children and the slightly lower proportion expecting three children is not essentially upset whether one considers the woman's education/training, her social environment or the income of the family. Although there are minor differences in the number of children the individual families have, the tendency is nevertheless for the smaller family to be found in the middle strata of the population - both with regard to the amount of income and length of education. This tendency, which, however, is less pronounced than what has previously been established. ${ }^{3}$ has been explained as an expression of social mobility - a large family should have a restrictive influence on the family's possibilities of climbing the social ladder. As mentioned only minor differences have been ascertained, which might indicate the number of children is not so important for the social mobility of the family as it previously was.

It has moreover been attempted to uncover how the style of life influences the family size. It has especially been examined whether at an early stage of marriage there may be a correlation between the expected family size and the desired style of life. With this in view the following conditions have been considered: the family's possession of and plans of acquiring durable consumer goods, the woman's ideals as to how the family should be housed while the children are young, the women's wishes as to spending her leisure time and her attitude to the importance of education/training.

However, these preferences with regard to the style of life have, as little as the woman's social background, contributed to explaining why some people expect more children than others. The result may indicate that either the family chooses its style of life and the number of children it wants independently, or that the Danish family is so small and the norm for having either two or three children so strong that it cannot be a question of a matter of choice for the family.

3 Per Nørrung: Differentiel Fertilitet (Differential Fertility). Examination Paper for the M. A. Degree in Sociology. Based on material from the investigation of Married Women in Family and Employment carried out by The Danish National Institute of Social Research, dating from 1965. 


\section{The Future Development of the Family Size}

The fertility investigation clearly shows that the norm for a Danish family having two or three children is very strong indeed, and that nothing seems to indicate that it will undergo any significant change in the near future.

In a somewhat longer perspective one can say that the reduction in the number of children of the individual families which started in the last century has to all appearances reached a stable minimum of two or three children, but that there is a slight tendency for the reduction to continue in the way that the few families who expect four children or more become constantly less.

If one looks at the social conditions, one can foresee a development where a larger number of women will receive an education/training and where more women will have occupational work. From what has been revealed by the investigation there is no clear indication that this trend will be accompanied by changes in the number of children. On the contrary, the little differences which have been established point in different directions. Certainly, the investigation shows that the large family with more than 3 children is more often excepted by highly educated women, but it also shows that the more permanently the woman is attached to the labour market, the less frequently will she expect four children or more.

The assumption of the family size having reached a minimum of two or three children is further supported by the women's responses to the other questions regarding the number of children included in the fertility investigation, viz.: the ideal number of children, the wanted number of children and the number of children if »one could live one's life over again». The ideal number of children expresses the number of children which the interviewed person finds ideal for a family whose economic conditions correspond to her own. The wanted number of children is based on the woman's own information about how many children she had when interviewed and whether she wanted more. The question was formulated: »Would you like to have more children». Finally the number of children "if one could live one's life over again» is based on the following question: "If you could imagine that you were able to start matrimonial life over again and could freely choose the number of children, how many would you like to have?» In Table 4 a comparison of the married women's responses to the four different questions has been made.

As will appear from this statement the concentration around the family of two or three children is heavier with regard to the ideal of family size and if the woman could "live her life over again» than is the case of the expectations of family size. Furthermore the statement clearly shows that only children and childless families are not considered ideal, just as a minor proportion of the women would like a family with less than two children if they could start matrimonial life over again. Thus when there is a larger proportion of women who except to have no children or only one child than the corresponding proportion 
$\mathrm{Table} 4$. Statement of the number of children the married women aged $15-49$ consider ideal, expect to have, want, and would like to have if they could "live their lives over again».

Number of children

\section{Ideal}

$<2$

$2-3$

$>3$

Other figures, do not

know not stated

Total
Expected

$\%$

11.9

65.5

17.4

16.5

1.2

100.1
Wanted

$\%$

7.5

68.9

20.9

2.6

99.9
"Life life over again"

\section{$\%$}

3.8

76.1

18.8

1.4

100.1

Number of interviewed women 2397

in respect of the ideal and the wishes of family size, it can reasonably be assumed that the proportion of families with less than two children will in future become less than the roughly 12 per cent stated here. Among other things there is reason to believe that medical progress with regard to remedying childlessness or reduced fertility will contribute to the future family size being more in keeping with the woman's own wishes and ideals. 